\title{
Pathophysiologic Treatment Approach to Irritant Contact Dermatitis
}

\section{Cheryl L. Eberting, $M D^{1, *}$ \\ Nicholas Blickenstaff, MS Alina Goldenberg, $B A^{2}$}

\author{
Address \\ ${ }^{*}, 1$ CherylLeeMD ${ }^{\circledR}$, Sensitive Skin Care and Alpine Dermatology \& Laser, 144 South \\ Main St, Alpine, UT 84004, USA \\ Email: CherylLee@CherylLeeMD.com \\ ${ }^{2}$ University of San Diego, School of Medicine, 9500 Gilman Dr, La Jolla, San Diego, \\ CA 92093, USA \\ Email: a1golden@ucsd.edu \\ ${ }^{3}$ University of Utah, School of Medicine, 30 North 1900 East, Salt Lake City, \\ UT 84123, USA \\ Email: Nick.Blickenstaff@utah.edu
}

Published online: 11 September 2014

(C) Springer International Publishing AG 2014

Keywords Allergen - Barrier dysfunction - Barrier repair, Ceramide - Cholesterol ester - Contact - Dermatitis . Dimethicone - Irritant - Niacinamide · Petrolatum

\section{Opinion statement}

Irritant contact dermatitis (ICD) is a commonly occurring non-specific cutaneous inflammatory response to topical chemical, physiologic, and biologic toxins. Direct damage to the skin induces barrier dysfunction, epidermal cell stimulation, and pro-inflammatory mediator release leading to a visibly variable, itchy cutaneous reaction. Workplace exposure of the hands to water, cleansers, and solvents remains the most common source of ICD. There is no diagnostic test for ICD, as such a diagnosis is based on history and clinical findings. Exclusion of allergic contact dermatitis, atopic dermatitis, and other xerotic conditions is a key part of the work-up. Prevention and treatment of ICD lies in the utilization of barrier protectants, incorporation of hydrating cleansers to decrease disruption of the barrier, and avoidance protocols and protective gear (fabrics, gloves, etc.). Therapeutic tools to treat ICD include acute anti-pruritic and antibacterial soaks, cutaneous barrier protectants such as petrolatum, paraffin, and dimethicone; lipid-laden moisturizers rich in wool wax alcohols, ceramides, and cholesterol esters and colloidal oatmeal based creams; and, when there is an eczematous component, the restrained use of antiinflammatory agents such as topical corticosteroids may be warranted. Future research in ICD pathophysiology will yield more precise treatment options for future patients and clinicians. 


\section{Introduction}

Irritant contact dermatitis (ICD) refers to skin inflammation that occurs as a result of exposure to exogenous caustic or irritating chemicals or physical agents that cause direct cytotoxic skin damage leading to skin barrier disruption, cellular changes, and release of proinflammatory mediators. ICD occurs via a nonimmunlogic mechanism in that it does not require prior sensitization; however, sufficient concentrations of exposed substances are required to elicit a reaction. Skin barrier function plays a pivotal role in the resistance to damage from these agents.

Hospitalization is rarely needed for ICD, with the exception of severe acute cases involving large surface areas from caustic agents such as Portland cement and hydrofluoric acid chemical burns. Chronic ICD can be induced subsequent to the frequent and repeated use of mildly irritating substances, such as soap, water, cleansers, and rubbing alcohol. Those with pre-existing skin disease [e.g., dry skin and atopic dermatitis (AD)], as well as infants and the elderly, are predisposed to developing ICD due to a less resilient epidermal barrier.

Previously believed to be a monomorphic process, ICD is now considered to be a complex biological syndrome with a distinct pathophysiology, diverse clinical appearance, and natural history. ICD is influenced by the physical and chemical properties of the irritating substance, concentration, mode of exposure, hostrelated susceptibility factors, and concomitant environmental factors. Treatment of acute ICD involves pruritus-relieving and infection-preventing soaks, whereas chronic ICD treatment consists of avoidance/ protection from known toxic substances, gentle cleansers, barrier creams, colloidal oatmeal-based creams, emollients, and lipid-rich moisturizers, which focus on improving barrier function and skin hydration. We set out to further understand the pathophysiology of irritant dermatitis and how it relates to current treatment options.

\section{Epidemiology}

\section{Pathogenesis}

Approximately $80 \%$ of the cases of contact dermatitis are due to ICD, with the remaining being accounted for by allergic contact dermatitis (ACD), protein contact dermatitis, systemic contact dermatitis, and contact urticaria [1]. Patients with $\mathrm{AD}$ are particularly vulnerable to irritants due to chronically impaired barrier function $[2,3]$. Research has demonstrated a different penetration profile in the stratum corneum of patients exposed to irritants with $\mathrm{AD}$ than in control subjects, suggesting altered barrier characteristics [2]. Anyone can develop ICD; however, individuals in the rubber, plastic, metal, petrochemical, and automotive industries are at greater risk of occupationally induced ICD, due to high rates of irritant exposure [4].

Although the precise cellular mechanisms remain to be elucidated, increasing evidence suggests the pathogenesis of ICD involves three main steps: irritation and disruption of the skin barrier, stimulation of the epidermal cells, and cytokine release leading to inflammation and skin changes Fig. 1. 


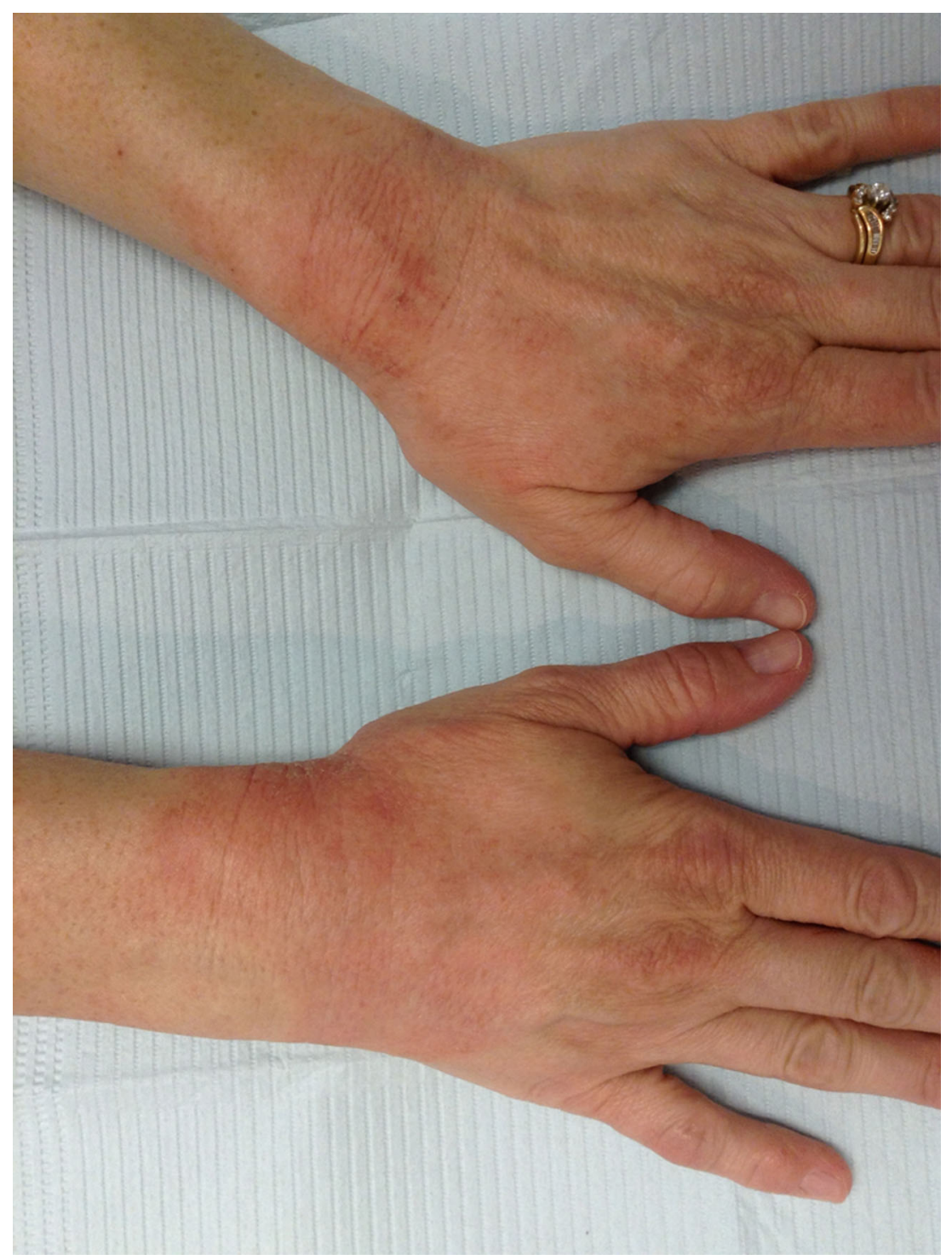

Figure. 1. Irritant dermatitis involving the hands of a mother who washes her hands very frequently

intrinsic structure of stacked cornified keratinocytes separated by highly ordered extracellular lipid bilayers [5]. These organized lipids prevent excessive loss of water from the body and limit the permeation of most topically applied substances. The protective effects of the stratum corneum are further enhanced by an acid mantle (one contributor to the acidic $\mathrm{pH}$ of the epidermis), a calcium gradient that influences desquamation and cellular turnover and differentiation of the epidermis, and the cutaneous immune system [6].

Exposure to irritants leads to stratum corneum damage and subsequent skin barrier impairment. Due to the complex nature of the stratum corneum there are many points of vulnerability. Excessive water loss and subsequent increased penetration of irritants and allergens, alteration in the epidermal calcium gradient, slow/deficient lipid production, and an increase in $\mathrm{pH}$ of the skin can all predispose one to developing ICD [7-9]. 
Trans-epidermal water loss (TEWL) is a reflection of the barrier function of the stratum corneum. When injured, the ability of the stratum corneum to maintain hydration is reduced, leading to increased TEWL and decreased water content in the skin. This impaired skin barrier facilitates the entry of irritants and is one of the fundamental defects in ICD pathophysiology [10].

Any substance capable of denaturing keratin, removing natural moisturizing factor, or interrupting the lipid bilayer component of the epidermis can increase TEWL. Irritants most frequently associated with increased TEWL include solvents, detergents, and excessive use of water and soap. Irritating potency of different surfactants and detergents has been previously studied using TEWL, with sodium lauryl sulfate (SLS), sodium dodecan sulphonate (SDS), and cocobetaine noted to most markedly influence the loss of water through the skin [11-13].

The major lipid species of the stratum corneum include ceramides (47\%), fatty acids (11\%), cholesterol (24\%), and cholesterol esters (18\%) [14]. The highly organized structure, concentration, and ratio of these lipids allows the epidermis to act as a barrier to irritants, allergens, and microbes, while limiting water loss and regulating temperature. Many skin conditions including ICD, xerosis, $\mathrm{AD}$, and aging are at least partially attributed to aberrations in the concentration and ratios of these lipids $[15,16]$.

Ceramides are a type of sphingolipid derived from lamellar granules. They generate stacked lipid structures that surround corneocytes to provide an impermeable barrier that limits TEWL and decreases leaching of natural moisturizing factor from the superficial skin layers. As one ages there is a sharp decrease in the production of intercellular lipids such as phytosphingosine and phytosphingosine-containing ceramides, which leads to increased susceptibility to dry skin and ICD $[17,18]$. Marked deficiency in ceramide 3 ( $\mathrm{N}$-acyl phytosphingosine) has also been well-documented in atopic skin and correlated to increased TEWL. Many common skin irritants such as such as SLS and SDS have been shown to reduce ceramide production. This is partially due to their ability to solubilize stratum corneum lipids. Examination of ceramide content following SLS application showed an inverse relationship between baseline ceramide weight and clinical irritation including erythema, scaling, dryness, and roughness [19].

A deficiency of cholesterol esters and an excessive relative concentration of cholesterol has been identified in naturally and SDS-induced xerotic skin $[17,20]$. Experimental and animal models have demonstrated that solvents such as acetone extract lipids from the stratum corneum [21] and anionic surfactants such as SLS damage keratin, involucrin, profilaggrin, and other protein structures responsible for preventing oversaturation of the stratum corneum and disorganization of the lipid bilayers [22-24].

The epidermal calcium gradient is felt to play a crucial role in mediating skin barrier homeostasis due to its influence on the terminal differentiation process of keratinocytes. Menon et al. showed that the intracellular calcium gradient disappears after barrier disruption with acetone, and reappears in parallel with lamellar body secretion and barrier recovery over a 24 -h period. These results show that barrier disruption results in loss of the epidermal calcium gradient, which may be the signal that initiates lamellar body secretion leading to barrier repair [25]. 
In acute-phase reactions of ICD, irritants penetrate the stratum corneum and directly activate epidermal keratinocytes, the key regulators of cytokine release and $\mathrm{T}$ cell activation. A cascade of events is initiated by damaged keratinocytes leading to activation of the innate immune system and subsequent release of pro-inflammatory cytokines, such as interleukin (IL)- $1 \alpha$, IL-1 $\beta$, IL-6, and tumor necrosis factor (TNF)- $\alpha$ [26]. TNF- $\alpha$ works in concert with IL- $1 \alpha$ and IL-1 $1 \beta$ to activate T cells, perpetuate cytokine and chemokine production, and upregulate expression of intercellular adhesion molecule-1 (ICAM-1) [27] - a characteristic feature of ICD. TNF- $\alpha$ and IL- $1 \alpha$ also trigger the release of CCL20 and CXCL8 chemokine signals that attract mononuclear and polymorphonuclear cells to the irritant injury site $[28,29]$. Additional active mediators such as CXCL8, CXCL1, and CCL2 are stimulated by fibroblasts to facilitate transport of Langerhans cells out of the epidermis [30, 31], while endothelial cells upregulate adhesion molecules to enhance delivery of immune cells into the skin [26].

Chronic ICD is poorly understood. It is hypothesized that chronic-phase reactions occur due to repeated exposure to solvents and surfactants that gradually extract lipids and water-retaining substances from the stratum corneum [32]. This leads to an increase in TEWL and the development of individual tolerance to certain irritants known as the 'hardening phenomenon.' The increase in TEWL is thought to then promote cell proliferation and hyper-

\section{Presentation} keratosis, which manifests as the chronic eczematoid irritant reaction [33].

\section{Diagnosis}

ICD has a variety of clinical manifestations ranging from mild skin dryness and erythema to more pronounced edema, coalescing vesicles, bullae, pustules, ulceration, and even skin necrosis. Lesions are usually sharply demarcated and confined to the contact area, while in ACD, lesions are less circumscribed and frequently disseminated. Common symptoms in ICD include burning, stinging, and soreness of the skin. Clinical distinction of ICD from ACD is difficult since both have similar clinical and histopathologic presentations, and often may coexist [34, 35].

The diagnosis of ICD is made based on history and clinical presentation of lesions [36]. Acute ICD related to more potent agents may be diagnosed based on distinct distribution, location, and time of onset of skin changes after exposure to the causative agent. A comprehensive clinical history focused on the diagnostic criteria listed in Table 1 can be helpful-no specific number of criteria is necessary; however, the more criteria that exist, the stronger the diagnosis [37].

\section{Treatment}

\section{Educating patients}

How to avoid irritants in the home and workplace is very important. Prevention techniques may not only help reduce the risk of ICD, but also ACD, as an 
Table 1. Irritant contact dermatitis diagnostic criteria*

$\begin{array}{ll}\begin{array}{l}\text { Subjective } \\ \text { Major }\end{array} & \text { Minor } \\ \begin{array}{ll}\text { 1) Onset: minutes-hours } & \text { 1) Onset: <2 weeks } \\ & \\ \text { 2) Symptoms: pain, } & \text { 2) Many people in the } \\ \text { burning, } & \text { environment } \\ \text { stinging, or discomfort } & \text { similarly } \\ \text { exceeding itching } & \text { affected }\end{array}\end{array}$

3) The healing process proceeds without plateau upon withdrawal

4) Negative Patch testing of exposure to substance in question

Objective

Major

1) Macular erythema, hyperkeratosis, or fissuring predominating over vesicular change

2) Glazed, parched, or scalded appearance of the epidermis

\section{Minor}

1) Sharp circumspection of the dermatitis

2) Evidence of gravitational influence, such as a dripping effect

3) Lack of tendency for spread of dermatitis

4) Vesicles juxtaposed closely to patches of erythema, erosions, bullae

*No specific number of these features needs to be present; the more criteria, the stronger the diagnosis

impaired skin barrier may increase the risk of allergen sensitization. Reducing contact with irritants such as soap, solvents, oils, alkalis, acids, or abrasive materials decreases the incidence of ICD.

\section{Acute care}

- Soak the affected area in cool or lukewarm water, saline (1 teaspoon/ pint), or Burow's solution (13\% aluminum acetate dissolved in water at a 1:40 concentration). Burow's solution has antibacterial properties, as well as an anti-inflammatory, cooling effect to decrease pruritus and prevent infection [38].

- Barrier creams protect against low-grade irritants, benefiting wetworkers who regularly utilize water, soaps, and detergents [40]. They also accelerate the rate of healing in damaged skin by increasing skin hydration and modifying endogenous epidermal lipids [41-43]. Petrolatum, paraffin wax, and dimethicone are commonly used skin protectants that are cheap and effective, as are TEWL inhibitors, in preventing ICD.

- Petrolatum is a complex semi-solid combination of paraffin wax, microcrystalline wax, and white mineral oil, and is considered to be the 
gold standard TEWL inhibitor [44]. Wigger-Alberti and Elsner confirmed the protective effects of petrolatum against four standard irritants-10\% SLS, $1 \%$ sodium hydroxide $(\mathrm{NaOH}), 30 \%$ lactic acid, and undiluted toluene-in the repetitive irritation test [45]. Paraffin is a mixture of saturated aliphatic hydrocarbons and is considered to be the most hydrophobic water-repelling agent; when combined with petrolatum, it is an extremely efficient TEWL inhibitor [46]. It is also a natural moisturizer that helps with exfoliation and healing dried or cracked skin.

- Dimethicone is a man-made polymer of the naturally occurring element silica or silicon. It is used as an emollient to soften and moisturize the skin, facilitate epidermal exfoliation, and provide a protective barrier from irritants $[47,48]$. Dimethicone-containing ointment has also proven to be highly effective in protecting the skin against contact irritants from sunscreens, intra-abdominal drainage, and the discharge of cutaneous ulcers $[49,50]$. However, use of dimethicone is becoming more limited due to reports of sensitization and inflammatory reactions to silicon polymers. Incubation of human monocytes demonstrated elevated levels of inflammatory cytokines including IL-1 $\beta$, IL-6, and TNF- $\alpha$ [51]. Furthermore, local lymph node assay in mice showed weak to moderate skin sensitization potential in four out of five silicon materials tested for skin sensitization $[52,53]$.

\section{Lipid-based moisturizers}

- Supplementation of the skin barrier with phytosphingosine and phytosphingosine-containing ceramides enhances barrier repair and further induces ceramide production. Niacinamide is a physiologically active form of vitamin B3 that increases epidermal thickness [54] and upregulates expression of serine palmitoyltransferase, the rate-limiting enzyme in sphingolipid synthesis [55]. This increase in ceramide production directly correlates with a reduction in TEWL in subjects with xerotic skin [55]. By creating a more formidable skin barrier using topical niacinamide, patients will be less prone to ICD following irritant exposure.

- In a model of ICD, skin was irritated with SDS and then treated with either a $1 \%$ cholesterol base or $1 \%$ cholesterol ester base. Skin treated with the cholesterol ester base showed improvements in conductance values while the cholesterol-treated skin did not. This suggests a benefit in restoring the cholesterol:cholesterol ester ratio with moieties that are deficient (cholesterol esters) rather than those present in relative excess (cholesterol) when treating ICD. 
- Protective gloves can be worn by people in constant or recurrent contact with water. However, they must be chosen carefully as prolonged exposure to waterproof gloves (as opposed to semipermeable or cotton gloves) may worsen ICD by exposure to the chemicals within the gloves [56].

\section{pH optimization}

- Healthy skin typically has an acidic stratum corneum with the $\mathrm{pH}$ ranging between 4.6 and 5.6. However, repeated exposure to alkaline substances such as soap, bleach, solvents, and even tap water can disturb the intricate $\mathrm{pH}$ balance and lead to a disrupted epidermal barrier.

- Maintaining pH helps sustain activity levels of lipid-producing enzymes $\beta$-glucocerebrosidase and acid sphingomyelinases [57, 58].

- Tap water can cause shifts in $\mathrm{pH}$, suboptimal to the lipid-producing $\mathrm{pH}$ range for up to $6 \mathrm{~h}$.

- Hyper-acidification of the skin may help prevent skin irritation. Experiments in mice showed that the stratum corneum in hairless mice treated with lactobionic acid and gluconolactone had enhanced barrier homeostasis and skin appearance while preventing skin irritation [59].

- Hydrophobic skin-protectant products may prevent an alkaline $\mathrm{pH}$ shift in the skin that is caused by soap, solvents, and water (author opinion, $\mathrm{CE}$ ). If the alkaline $\mathrm{pH}$ shift occurs, with time the skin's innate buffering systems can restore the naturally acidic $\mathrm{pH}$ and lipid production by the $\mathrm{pH}$-dependent enzymes.

\section{Anti-inflammatory treatments}

- Topical corticosteroids have not been experimentally proven as useful in the treatment of ICD when compared to steroid-free vehicle and untreated controls [60]. However, they are often used in a limited scope to treat acute eczematous ICD as they can help decrease inflammation and itch. Prolonged use of topical corticosteroids is not advised as it may lead to skin atrophy and actual increase in ICD susceptibility.

- Niacinamide has also been shown to be beneficial in treating a variety of inflammatory skin diseases [61-63] secondary to inhibition of leukocyte chemotaxis, lysosomal enzyme release, lymphocytic transformation, mast cell degranulation, vasoactive amines, preservation of intracellular coenzyme homeostasis, and decreased sebum production $[64,65]$.

- A lipid fraction, isostearyl isostearate, has recently been identified as one of the most effective lipid-based TEWL inhibitors in the world; 
however, its ability to prevent skin contact with irritants remains to be evaluated [66-68].

- Identification of the specific lipids deficient in ICD and then supplementing them directly to the irritated skin may be more effective than supplying normal skin physiologic levels of lipids [14, 69].

- Newly developed topical calcineurin inhibitors such as pimecrolimus and tacrolimus may be used for their antiinflammatory mechanisms without the atrophy risk carried by topical corticosteroids [70, 71].

- $18 \beta$-Glycyrrhetinic acid is a new, potentially viable anti-inflammatory agent due to its corticosteroid-like anti-inflammatory effects, without the corticosteroid side effects. In vitro, $18 \beta$-glycyrrhetinic acid has been found to attenuate the generation of excessive pro-inflammatory genes NO, PGE2, and ROS by inhibiting nuclear factor (NF)-кB and PI3K activity [72].

\section{Pediatric considerations}

ICD is as common in children as in adults. Common presentations in children include irritant diaper dermatitis, also known as 'napkin dermatitis,' which presents as erythematous patches with/without scaling that spare the intertriginous folds and liplicking dermatitis $[73 \bullet \bullet, 74]$. Studies show that children under 8 years old are more susceptible to cutaneous absorption of chemicals and irritant reactions [75]. The infant skin barrier develops postnatally throughout the first year of life. Infant skin has a thinner stratum corneum and papillary dermis, as well as increased ability to absorb water [76, 77]. Additionally, direct skin injury that perturbs the skin barrier can occur during removal of various adhesive tapes and monitors frequently found on infants while in the hospital [78]. Moreover, infant skin has a $\mathrm{pH}$ of 5.5, and only begins to develop its acid mantle at birth, so it is missing the protective acidic barrier found in adult skin. Similar to adults, children with inherently disrupted cutaneous barrier function, such as those with $\mathrm{AD}$, have a predisposition to developing ICD.

\section{Compliance with Ethics Guidelines}

\section{Conflict of Interest}

Cheryl Lee Eberting, MD is the founder and CEO of CherylLeeMD ${ }^{\circledR}$, Sensitive Skin Care and is the inventor of the TrueLipids ${ }^{\circledR}$ skin barrier repair technology.

Alina Goldenberg declares that she has no conflict of interest.

Nicholas Blickenstaff declares that he has no conflict of interest.

\section{Funding Source}

No funding was secured for this study.

\section{Human and Animal Rights and Informed Consent}

This article does not contain any studies with human or animal subjects performed by any of the authors. 


\section{References and Recommended Reading}

Papers of particular interest, published recently, have been highlighted as:

$\bullet \quad$ Of major importance

1. Marks Jr JG, Elsner P, DeLeo V. Contact and occupational dermatology. 3rd ed. St. Louis: Mosby; 2002.

2. Jakasa I, de Jongh CM, Verberk MM, Bos JD, Kezić S. Percutaneous penetration of sodium lauryl sulphate is increased in uninvolved skin of patients with atopic dermatitis compared with control subjects. $\mathrm{Br}$ J Dermatol. 2006;155:104-9.

3. Jakasa I, Verberk MM, Esposito M, Bos JD, Kezic S. Altered penetration of polyethylene glycols into uninvolved skin of atopic dermatitis patients. J Invest Dermatol. 2007;127:129-34.

4. Keegel T, Moyle M, Dharmage S, Frowen K, Nixon R. The epidemiology of occupational contact dermatitis (1990-2007): a systematic review. Int J Dermatol. 2009;48:571-8.

5. $\quad$ Alain Boucaud, Laurent Machet. Chapter 54: Transdermal Transport by Phonophoresis. In: Percutaneous Absorption. CRC Press; 2005. p. 739-58. http://www.crcnetbase.com/doi/abs/10.1201/ 9780849359033.ch54. Accessed 23 Apr 2014

6. Watt FM. Terminal differentiation of epidermal keratinocytes. Curr Opin Cell Biol. 1989;1:1107-15.

7. Malajian D, Belsito DV. Cutaneous delayed-type hypersensitivity in patients with atopic dermatitis. J Am Acad Dermatol. 2013;69:232-7.

8. Fonacier LS, Aquino MR. The role of contact allergy in atopic dermatitis. Immunol Allergy Clin North Am. 2010;30:337-50.

9. Shaughnessy CN, Malajian D, Belsito DV. Cutaneous delayed-type hypersensitivity in patients with atopic dermatitis: reactivity to topical preservatives. J Am Acad Dermatol. 2014;70:102-7.

10. Yoshiike T, Aikawa Y, Sindhvananda J, Suto H, Nishimura K, Kawamoto T, et al. Skin barrier defect in atopic dermatitis: increased permeability of the stratum corneum using dimethyl sulfoxide and theophylline. J Dermatol Sci. 1993;5:92-6.

11. Tupker RA, Pinnagoda J, Coenraads P-J, Nater JP. The influence of repeated exposure to surfactants on the human skin as determined by transepidermal water loss and visual scoring. Contact Dermatitis. 1989;20:108-14.

12. Van der Valk PG, Nater JP, Bleumink E. Skin irritancy of surfactants as assessed by water vapor loss measurements. J Invest Dermatol. 1984;82:291-3.

13. Lammintausta K, Maibach HI, Wilson D. Irritant reactivity in males and females. Contact Dermatitis. 1987; 17:276-80.

14. Elias PM. Epidermal barrier function: intercellular lamellar lipid structures, origin, composition and metabolism. J Control Release. 1991;15: 199-208.
15. Madison KC. Barrier function of the skin: "la raison d'être" of the epidermis. J Invest Dermatol. 2003;121:231-41.

16. Wollenberg A, Kraft S, Hanau D, Bieber T. Immunomorphological and Ultrastructural Characterization of Langerhans Cells and a Novel, Inflammatory Dendritic Epidermal Cell (IDEC) Population in Lesional Skin of Atopic Eczema. J Invest Dermatol. 1996;106:446-53.

17. Fulmer AW, Kramer GJ. Stratum corneum lipid abnormalities in surfactant-induced dry scaly skin. J Invest Dermatol. 1986;86:598-602.

18. Macheleidt O, Kaiser HW, Sandhoff K. Deficiency of epidermal protein-bound omega-hydroxyceramides in atopic dermatitis. J Invest Dermatol. 2002;119:166-73.

19. Di Nardo A, Sugino K, Wertz P, Ademola J, Maibach HI. Sodium lauryl sulfate (SLS) induced irritant contact dermatitis: a correlation study between ceramides and in vivo parameters of irritation. Contact Dermatitis. 1996;35:86-91.

20. Saint-Leger D, Francois AM, Leveque JL, Stoudemayer TJ, Kligman AM, Grove G. Stratum corneum Lipids in Skin Xerosis. Dermatology. 1989;178:151-5.

21. Fartasch M. Ultrastructure of the epidermal barrier after irritation. Microsc Res Tech. 1997;37:193-9.

22. Ponec M, Kempenaar J. Use of human skin recombinants as an in vitro model for testing the irritation potential of cutaneous irritants. Skin Pharmacol Off J Skin Pharmacol Soc. 1995;8:49-59.

23. Elias PM, Ahn SK, Denda M, Brown BE, Crumrine D, Kimutai LK, et al. Modulations in epidermal calcium regulate the expression of differentiation-specific markers. J Invest Dermatol. 2002;119:1128-36.

24. Fartasch M, Schnetz E, Diepgen TL. Characterization of detergent-induced barrier alterations - effect of barrier cream on irritation. J Investig Dermatol Symp Proc Soc Investig Dermatol Inc Eur Soc Dermatol Res. 1998;3:121-7.

25. Menon GK, Elias PM, Lee SH, Feingold KR. Localization of calcium in murine epidermis following disruption and repair of the permeability barrier. Cell Tissue Res. 1992;270:503-12.

26. Lee HY, Stieger M, Yawalkar N, Kakeda M. Cytokines and Chemokines in Irritant Contact Dermatitis. Mediators Inflamm. 2013;2013:916497. http:// www.ncbi.nlm.nih.gov/pmc/articles/PMC3858878/. Accessed 21 May 2014.

27. Nosbaum A, Vocanson M, Rozieres A, Hennino A, Nicolas J-F. Allergic and irritant contact dermatitis. Eur J Dermatol. 2009; 19:325-32.

28. Nakayama T, Fujisawa R, Yamada H, Horikawa T, Kawasaki H, Hieshima K, et al. Inducible expression of a CC chemokine liver- and activation-regulated 
chemokine (LARC)/macrophage inflammatory protein (MIP)-3 alpha/CCL20 by epidermal keratinocytes and its role in atopic dermatitis. Int Immunol. 2001;13:95103.

29. Liao F, Rabin RL, Smith CS, Sharma G, Nutman TB, Farber JM. CC-chemokine receptor 6 is expressed on diverse memory subsets of $\mathrm{T}$ cells and determines responsiveness to macrophage inflammatory protein 3 alpha. J Immunol. 1999;162:186-94.

30. Newby CS, Barr RM, Greaves MW, Mallet AI. Cytokine release and cytotoxicity in human keratinocytes and fibroblasts induced by phenols and sodium dodecyl sulfate. J Invest Dermatol. 2000;115:292-8.

31. Ouwehand K, Scheper RJ, de Gruijl TD, Gibbs S. Epidermis-to-dermis migration of immature Langerhans cells upon topical irritant exposure is dependent on CCL2 and CCL5. Eur J Immunol. 2010;40:2026-34.

32. Bolognia JL, Jorizzo JL, Schaffer JV, editors. Dermatology: 2-Volume Set: Expert Consult Premium Edition - Enhanced Online Features and Print. 3rd ed. Philadelphia: Saunders; 2012.

33. Loden M, Maibach HI. Dry Skin and Moisturizers: Chemistry and Function. Boca Raton: CRC Press; 1999.

34. Kanerva L, Elsner P, Wahlberg JE, Maibach HI. Condensed Handbook of Occupational Dermatology. Berlin: Springer; 2003.

35. Scheynius A, Fischer T, Forsum U, Klareskog L. Phenotypic characterization in situ of inflammatory cells in allergic and irritant contact dermatitis in man. Clin Exp Immunol. 1984;55:81-90.

36. Ale IS, Maibach HA. Diagnostic approach in allergic and irritant contact dermatitis. Expert Rev Clin Immunol. 2010;6:291-310.

37. Rietschel RL. Clues to an accurate diagnosis of contact dermatitis. Dermatol Ther. 2004;17:224-30.

38. Thorp MA, Kruger J, Oliver S, Nilssen EL, Prescott CA. The antibacterial activity of acetic acid and Burow's solution as topical otological preparations. J Laryngol Otol. 1998; 112:925-8.

39. Zhai H, Maibach HI. Anti-irritants agents for the treatment of irritant contact dermatitis: clinical and patent perspective. Recent Patients Inflamm Allergy Drug Discov. 2012;6:169-85.

40. Davidson CL. Occupational contact dermatitis of the upper extremity. Occup Med. 1994;9:59-74.

41. Wertz PW, Downing DT. Metabolism of topically applied fatty acid methyl esters in BALB/C mouse epidermis. J Dermatol Sci. 1990;1:33-7.

42. Zhai H, Maibach HI. Moisturizers in preventing irritant contact dermatitis: an overview. Contact Dermatitis. 1998;38:241-4.

43. Ramsing DW, Agner T. Preventive and therapeutic effects of a moisturizer. An experimental study of human skin. Acta Derm Venereol. 1997;77:335-7.

44. Patzelt A, Lademann J, Richter H, Darvin ME, Schanzer $S$, Thiede $G$, et al. In vivo investigations on the penetration of various oils and their influence on the skin barrier. Skin Res Technol. 2012;18:364-9.
45. Wigger-Alberti W, Elsner P. Petrolatum prevents irritation in a human cumulative exposure model in vivo. Dermatol Basel Switz. 1997;194:247-50.

46. Ray BR, Bartell F. Hysteresis of contact angle of water on paraffin. Effect of surface roughness and of purity of paraffin. J Colloid Sci. 1953;8:214-23.

47. Fluhr JW, Elsner P, Berardesca E, Maibach HI. Bioengineering of the Skin: Water and the Stratum Corneum. 2nd ed. Boca Raton: CRC Press; 2013.

48. Zhai H, Brachman F, Pelosi A, Anigbogu A, Ramos MB, Torralba $\mathrm{MC}$, et al. A bioengineering study on the efficacy of a skin protectant lotion in preventing SLSinduced dermatitis. Skin Res Technol. 2000;6:77-80.

49. Nichols K, Desai N, Lebwohl MG. Effective sunscreen ingredients and cutaneous irritation in patients with rosacea. Cutis. 1998;61:344-6.

50. Carter BN, Sherman RT. Dimethicone (silicone) skin protection in surgical patients. AMA Arch Surg. 1957;75:116-7.

51. Anderson JM, Ziats NP, Azeez A, Brunstedt MR, Stack S, Bonfield TL. Protein adsorption and macrophage activation on polydimethylsiloxane and silicone rubber. J Biomater Sci Polym Ed. 1995;7:159-69.

52. Oprea ML, Schnöring H, Sachweh JS, Ott H, Biertz J, Vazquez-Jimenez JF. Allergy to pacemaker silicone compounds: recognition and surgical management. Ann Thorac Surg. 2009;87:1275-7.

53. Rubio A, Ponvert C, Goulet O, Scheinmann P, De Blic J. Allergic and nonallergic hypersensitivity reactions to silicone: a report of one case. Allergy. 2009;64:1555-6.

54. Mohammed D, Crowther JM, Matts PJ, Hadgraft J, Lane $\mathrm{ME}$. Influence of niacinamide containing formulations on the molecular and biophysical properties of the stratum corneum. Int J Pharm. 2013;441:192-201.

55. Tanno O, Ota Y, Kitamura N, Katsube T, Inoue S. Nicotinamide increases biosynthesis of ceramides as well as other stratum corneum lipids to improve the epidermal permeability barrier. Br J Dermatol. 2000;143:524-31.

56. Kwon S, Campbell LS, Zirwas MJ. Role of protective gloves in the causation and treatment of occupational irritant contact dermatitis. J Am Acad Dermatol. 2006;55:891-6.

57. Holleran WM, Takagi Y, Imokawa G, Jackson S, Lee JM, Elias PM. beta-Glucocerebrosidase activity in murine epidermis: characterization and localization in relation to differentiation. J Lipid Res. 1992;33:1201-9.

58. Bowser PA, Gray GM. Sphingomyelinase in pig and human epidermis. J Invest Dermatol. 1978;70:331-5.

59. Berardesca E, Distante F, Vignoli GP, Oresajo C, Green B. Alpha hydroxyacids modulate stratum corneum barrier function. Br J Dermatol. 1997;137:934-8.

60. Levin C, Maibach HI. An overview of the efficacy of topical corticosteroids in experimental human nickel contact dermatitis. Contact Dermatitis. 2000;43:317-21.

61. Soma Y, Kashima M, Imaizumi A, Takahama H, Kawakami T, Mizoguchi M. Moisturizing effects of 
topical nicotinamide on atopic dry skin. Int J Dermatol. 2005;44:197-202.

62. Niren NM, Torok HM. The Nicomide Improvement in Clinical Outcomes Study (NICOS): results of an 8week trial. Cutis. 2006;77:17-28.

63. Draelos ZD, Ertel K, Berge C. Niacinamide-containing facial moisturizer improves skin barrier and benefits subjects with rosacea. Cutis. 2005;76:135-41.

64. Fivenson DP. The mechanisms of action of nicotinamide and zinc in inflammatory skin disease. Cutis. 2006;77:5-10.

65. Draelos ZD, Matsubara A, Smiles K. The effect of $2 \%$ niacinamide on facial sebum production. J Cosmet Laser Ther Off Publ Eur Soc Laser Dermatol. 2006;8:96-101.

66. Pennick G, Harrison S, Jones D, Rawlings AV. Superior effect of isostearyl isostearate on improvement in stratum corneum water permeability barrier function as examined by the plastic occlusion stress test. Int J Cosmet Sci. 2010;32:304-12.

67. Pennick G, Chavan B, Summers B, Rawlings AV. The effect of an amphiphilic self-assembled lipid lamellar phase on the relief of dry skin. Int J Cosmet Sci. 2012;34:567-74.

68. Dederen JC, Chavan B, Rawlings AV. Emollients are more than sensory ingredients: the case of Isostearyl Isostearate. Int J Cosmet Sci. 2012;34:502-10.

69. Rawlings AV. Trends in stratum corneum research and the management of dry skin conditions. Int J Cosmet Sci. 2003;25:63-95.

70. Belsito DV, Fowler JF, Marks JG, Pariser DM, Hanifin J, Duarte IAG, et al. Pimecrolimus cream $1 \%$ : a potential new treatment for chronic hand dermatitis. Cutis. 2004;73:31-8.

71. Mensing $\mathrm{CO}$, Mensing $\mathrm{CH}$, Mensing $\mathrm{H}$. Treatment with pimecrolimus cream $1 \%$ clears irritant dermatitis of the periocular region, face and neck. Int J Dermatol. 2008;47:960-4.

72. Wang C-Y, Kao T-C, Lo W-H, Yen G-C. Glycyrrhizic Acid and 18ß-Glycyrrhetinic Acid Modulate Lipopolysaccharide-Induced Inflammatory Response by Suppression of NF- $\kappa$ B through PI3K p $110 \delta$ and p110 $\gamma$ Inhibitions. J Agric Food Chem. 2011;59:772633.

73.• James WD, Berger T, Elston D. Andrew's Diseases of the Skin: Clinical Dermatology. Philadelphia: Elsevier Health Sciences; 2011.

Compact, comprehensive overview of dermatology that provides great detail on pediatric manifestations of irritant contact dermatitis.

74. Atherton DJ. A review of the pathophysiology, prevention and treatment of irritant diaper dermatitis. Curr Med Res Opin. 2004;20:645-9.

75. Denig NI, Hoke AW, Maibach HI. Irritant contact dermatitis. Clues to causes, clinical characteristics, and control. Postgrad Med. 1998;103:199-200. 207-8, 212-3.

76. Infant skin barrier maturation in the first year of life. J. Am. Acad. Dermatol. 2007;56:AB153.

77. Stamatas GN, Nikolovski J, Luedtke MA, Kollias N, Wiegand BC. Infant skin microstructure assessed in vivo differs from adult skin in organization and at the cellular level. Pediatr Dermatol. 2010;27:125-31.

78. Darmstadt GL, Dinulos JG. Neonatal Skin Care. Pediatr Clin North Am. 2000;47:757-82. 